\title{
Spatio-temporal estimation of basic and effective reproduction number of COVID-19 and post-lockdown transmissibility in Bangladesh
}

\author{
Al-Ekram Elahee Hridoy ${ }^{1}$ Imrul Hasan Tipo ${ }^{2} \cdot$ Md. Shamsudduha Sami $^{3}$ - Md. Ripon Babu ${ }^{2}$. \\ Md. Sayem Ahmed ${ }^{4}$ Syed Masiur Rahman ${ }^{5} \cdot$ Shekh Md. Shajid Hasan Tusher $^{1} \cdot$ Kazi Jihadur Rashid $^{6}{ }^{(0)} \cdot$ \\ Mohammad Naim ${ }^{7}$
}

Received: 20 March 2021/Revised: 28 May 2021 / Accepted: 4 June 2021 / Published online: 28 June 2021

(C) Korean Spatial Information Society 2021

\begin{abstract}
The ongoing COVID-19 pandemic has caused unprecedented public health concern in Bangladesh. This study investigated the role of Non-Pharmaceutical Interventions on COVID-19 transmission and post-lockdown scenarios of 64 administrative districts and the country as a whole based on the spatiotemporal variations of effective reproduction number $\left(R_{\mathrm{t}}\right)$ of COVID-19 incidences. The daily confirmed COVID-19 data of Bangladesh and its administrative districts from March 8, 2020, to March 10, 2021 , were used to estimate $R_{\mathrm{t}}$. This study finds that the maximum value of $R_{\mathrm{t}}$ reached $4.15(3.43,4.97,95 \% \mathrm{CI})$ in late March 2020, which remained above 1 afterwards in most of the districts. Containment measures are moderately effective in reducing transmission by $24.03 \%$. The $R_{\mathrm{t}}$ was established below 1 from early December 2020 for overall Bangladesh and a gradual increase of $R_{\mathrm{t}}$ above 1 has been
\end{abstract}

Kazi Jihadur Rashid

jihadrashid.gis@gmail.com

1 Department of Geography and Environmental Studies, University of Chittagong, Chattogram 4331, Bangladesh

2 Department of Biochemistry and Molecular Biology, University of Chittagong, Chattogram 4331, Bangladesh

3 Department of Geography and Environment, Jagannath University, Dhaka 1100, Bangladesh

4 Department of Pharmacy, East West University, Dhaka 1212, Bangladesh

5 Center for Environment \& Water, Research Institute, King Fahd University of Petroleum \& Minerals, KFUPM Box 713, Dhahran 31261, Saudi Arabia

6 Center for Environmental and Geographic Information Services (CEGIS), Dhaka 1212, Bangladesh

7 Department of Electrical and Computer Engineering, North South University, Dhaka 1229, Bangladesh seen from early February 2021. The basic reproduction number $\left(R_{0}\right)$ in Bangladesh probably varied around 2.02 $(1.33-3.28,95 \% \mathrm{CI})$. This study finds a significant positive correlation $(\mathrm{r}=0.75)$ between population density and COVID-19 incidence and explaining 56\% variation in Bangladesh. The findings of this study are expected to support the policymakers to adopt appropriate measures for curbing the COVID-19 transmission effectively.

Keywords Bangladesh · Basic reproduction number . COVID-19 · Effective reproduction number .

Epidemiology $\cdot$ Non-pharmaceutical Intervention · SARS$\mathrm{CoV}-2$

\section{Introduction}

The ongoing coronavirus disease (nCoV-19), caused by the SARS-CoV-2 strain, has caused unprecedented public health concern worldwide. The World Health Organization (WHO) declared COVID-19 as a global pandemic on March 11, 2020. With the emergence of a novel infectious disease, various transmissibility metrics are used to quantify how infectious it is. Among various metrics, the basic reproduction number $\left(R_{0}\right)$ is most utilized and can track the disease dynamics in an environment when everyone is susceptible to the disease. $R_{0}$ is regarded as an estimate of contagiousness that is a function of human behavior and pathogens' biological characteristics [1]. Researchers across the world have exercised many models to assist policymakers in fighting COVID-19. To assess the effectiveness of containment measures and design non-pharmaceutical interventions (NPIs), accurate estimation of $R_{0}$ and $R_{\mathrm{t}}$ is of paramount importance. 
The first confirmed case in Bangladesh was identified on March 8 2020. In response to the outbreak, the Government of Bangladesh (GoB) has implemented various non-pharmaceutical interventions (NPIs) to contain the transmission. Bangladesh has taken several types of containment measures intending to reduce COVID-19 transmission. These NPIs have been implemented with essential modifications, like whole country and zone-based. Only essential items have come under consideration from the group of containment and closure policies. Require closing (or work from home) for some sectors or categories of workers, from early May to mid-May for the entire country and require closing (or work from home) for all-but-essential workplaces (e.g., grocery stores, doctors), from mid-May to late May for the whole country. In targeted places, these measures were undertaken from mid-March to late March and mid-July to early December.

However, there is an ongoing debate whether measures have been adopted adequately and implemented efficiently [2]. Lack of adequate NPIs, it can be assumed that the COVID-19 pandemic will exacerbate in Bangladesh. It remained fuzzy how adopted containment strategies were effective in curtailing COVID-19 transmission. As Bangladesh lifted lockdowns due to economic burden, it is unclear how SARS-CoV-2 transmission varied across the country. Since the COVID-19 pandemic is still ongoing, relaxation of containment measures is accountable for weakening the foundation for control of infectious disease by declining caution and awareness [3].

Bangladesh is one of the world's most populous countries, with a high poverty rate and dense population, implying greater COVID-19 exposure [4]. Jahangiri et al. [5] mentioned that transmission of COVID-19 has a high sensitivity to population size. Wong and $\mathrm{Li}$ [6] found that population density is an effective predictor of COVID-19 cases in the USA and that places with high population density levels are expected to have high cases. Moreover, $R_{\mathrm{t}}$ varies with the social dynamics, and regional $R_{\mathrm{t}}$ estimation may guide easing or imposing local control measures [7]. Therefore, given the urgency of the COVID-19 situation, this study aimed to assess the effectiveness of containment measures and estimate $R_{\mathrm{t}}$ for Bangladesh and post-lockdown throughout the country. It is crucial to scrutinize and examine the dynamics of COVID-19 and the necessity of evaluating different containment strategies to gain a better overview of continuing conditions that might help adjust and strengthen public health intervention schemes. We aimed to estimate a plausible in Bangladesh for the early outbreak of COVID-19 using several serial intervals from other countries. In addition, we hypothesized that population density could be an influential factor in spreading COVID-19 in Bangladesh. Thus, this study also assessed the association between population density and COVID-19. Since Bangladesh is in the midst of this COVID-19 outbreak, this study will highlight the importance of the real-time monitoring of COVID-19 transmission and the necessity of containment measures to curb the transmission effectively. This study might be an essential reference for advanced studies on the transmission pattern of SARS-CoV-2 across Bangladesh.

\section{Materials and method}

\subsection{Data source}

Daily data of confirmed COVID-19 cases in Bangladesh was included in this study from March 8, 2020, to March 10, 2021. The COVID-19 data used in this study were retrieved from Johns Hopkins University's GitHub repository. The district-wise COVID-19 incidences were retrieved from the online version of Institute of Epidemiology Disease Control and Research (IEDCR). Districtwise data is available from July 82020 to December 15 2020 [8]. The NPIs information was retrieved from Github repository Oxford Covid-19 Government Response Tracker (OxCGRT). District-level population and population density data has been retrieved from Bangladesh Bureau of Statistics (BBS) [9].

\subsection{Study area}

Bangladesh is a riverine country located in $\left(23.6850^{\circ} \mathrm{N}\right.$, $90.3563^{\circ} \mathrm{E}$ ) the south-eastern part of Asia, which shared a border with India and Myanmar. It is one of the most densely populated countries in the world with an average of 964 inhabitants per square kilometer and 142,319 thousand population [9]. Whole country has been selected as a study area, including administrative 8 divisions and 64 districts shown in Fig. 1. 



$88^{\circ} 0^{\prime} 0^{\prime \prime} \mathrm{E}$
$89^{\circ} 0^{\prime} 0^{\prime \prime} \mathrm{E}$
$90^{\circ} 0^{\prime} 0^{\prime \prime} \mathrm{E}$
$91^{\circ} 0^{\prime} 0^{\prime \prime} \mathrm{E}$
$92^{\circ} 0^{\prime} 0^{\prime \prime} \mathrm{E}$
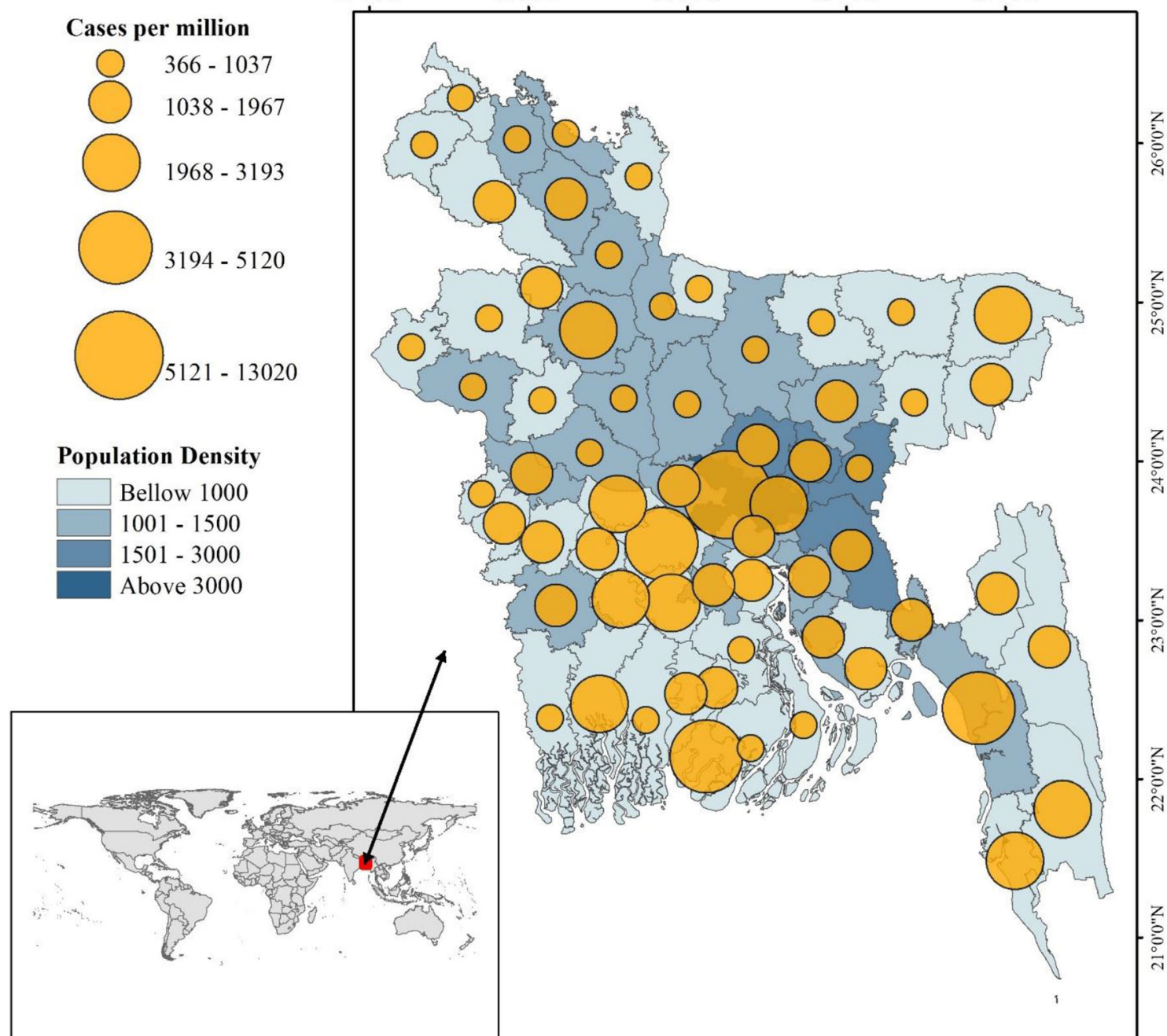

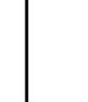
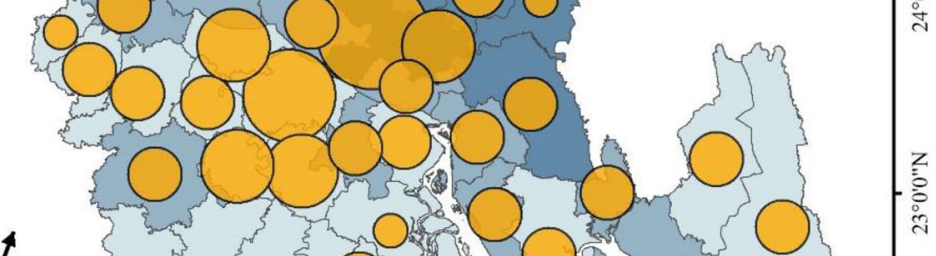

bag
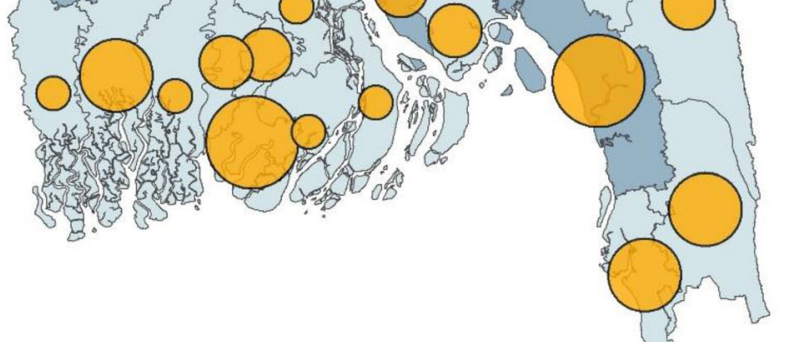

Fig. 1 Study area map showing district-wise distribution COVID-19 cases and population density

\subsection{Methods}

\subsubsection{Estimation of basic and effective reproduction number}

$R_{0}$ represents the average number of people infected by one infectious individual [1]. If $R_{0}$ is greater than 1 , the number of infected people is likely to increase exponentially and the epidemic will continue. If $R_{0}$ is less than 1 , the outbreak is likely to die out on its progression course. The $R_{0}$ is extensively used to evaluate how an epidemic will spread through a population and design various non-pharmaceutical interventions (NPIs) as exit strategies. The $R_{0}$ is estimated early phase of an outbreak when any NPIs are not adopted to control the transmission. This study utilized $R_{0}$ package of $\mathrm{R}$ software [10] with Exponential Growth (EG) and Maximum Likelihood (ML) methods to estimate $R_{0}$.
When various intervention measures are implemented to contain a disease transmission, the time-varying version of the reproductive number $R_{\mathrm{t}}$ can be estimated. Similar to the concept of $R_{0}$, a $R_{\mathrm{t}}$ value over 1 indicates the disease is transmitting exponentially, whereas less than 1 indicates the transmission is decreasing. The $R_{0}$ will not be constant over time because actions will be taken by policymakers (i.e., lockdown and socio-behavioral factors). The timevarying variation of an epidemic can be estimated by the effective reproduction number over time, $R_{\mathrm{t}}$ [11-13]. To estimate $R_{\mathrm{t}}$, we utilized EpiEstim [12] in $\mathrm{R}$ software environment. It is demonstrated that the method of Cori [12] most accurately estimates the instantaneous reproductive number in real-time since it assumes minimal assumption and uses only past data and minimal parametric assumptions [14].

$R_{\mathrm{t}}$ was estimated by Eq. (1) which can be explained as the ratio of the number of new infections generated in step 
$t, I_{\mathrm{t}}$, to the total infectiousness of infected individuals at time $t$, the sum of infection incidence up to the time step $t$ $a$, weighted by the infectivity function $w_{s}[15]$.

$R_{t}=\sum_{s=1}^{t} I_{t-a} w_{s}$

The estimate- $\mathrm{R}$ function in the EpiEstim library [12] assumes a gamma distribution of the serial interval and models the transmission of the infection using a Poisson likelihood to estimate the effective reproduction number [16]. We used a discrete gamma distribution with a mean of 4.7 days and a standard deviation of 2.9 [17]. The $R_{\mathrm{t}}$ was estimated on a 7-day sliding window to account for discreteness in data. All analyses were carried out in R statistical software and graphical presentations in Python 3 and ArcGIS 10.5.

\subsubsection{Serial interval and effectiveness of lockdown}

A few epidemiological quantities are needed to understand and quantify the transmissibility of a novel infectious disease, such as the distribution of the generation time, serial interval and incubation period. However, generation time often difficult to find out in early outbreaks; thus, the generation time has been approximated by the serial interval [18]. Since, there is no published literature on generation time and serial interval time of COVID-19 in
Bangladesh. Thus, we have adopted eleven published literature with parameterized serial intervals [13, 19]. To estimate the effectiveness of lockdown measures, the mean $R_{\mathrm{t}}$ before lockdown (early March to late March 2020) and consecutive 15 days $R_{\mathrm{t}}$ of lockdown period from late March to late May 2020 has been considered.

\subsubsection{Simple linear regression}

To assess the correlation between COVID-19 incidence and population density, we employed simple linear regression as the following Eq. (2).

$Y=\beta_{0}+\beta_{1} \cdot \mathrm{PD}+\varepsilon$

where $Y$ denotes total confirmed cases per million as a dependent variable, $\beta_{0}$ is the regression intercept, $\mathrm{PD}$ is the population density as an independent variable, $\beta_{1}$ is the regression coefficient and $\varepsilon$ is the error term.

\section{Results}

\subsection{COVID-19 scenario in Bangladesh}

The monthly change of COVID-19 dynamics in Bangladesh is illustrated in Fig. 2. The number of cases has increased from May, and a higher number of cases was observed in June and July, indicating a fully propagated

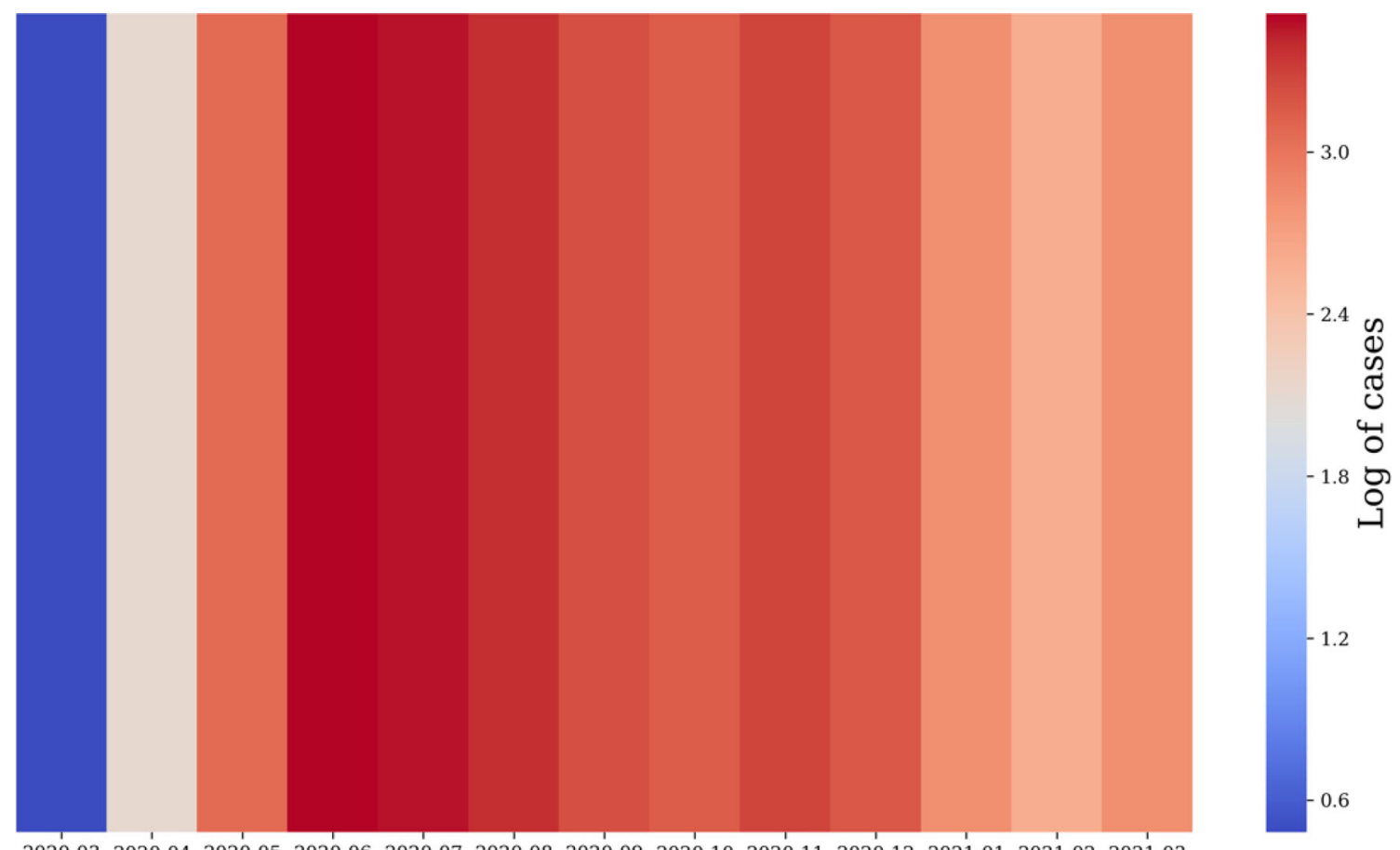

2020-03 2020-04 2020-05 2020-06 2020-07 2020-08 2020-09 2020-10 2020-11 $2020-12 \quad 2021-01 \quad 2021-02 \quad 2021-03$ Dates

Fig. 2 The dynamics of COVID-19 in Bangladesh. The total monthly cases are in logarithmic scale $\log (\mathrm{N}+1)$ 
epidemic. However, the number of cases declined from September 2020.

The COVID-19 scenarios in 64 administrative districts of Bangladesh under eight divisions are shown in Fig. 3. Barishal has tallied the highest number of cases from July to September and declined from December. Chittagong district has faced the maximum number of cases, a notable declination has been seen from July to October, but a substantial increase started from December. In Khulna, maximum number of cases ranged from July to September.
Dhaka city has recorded the highest number of cases with an almost homogeneous pattern. From July to August, Mymensingh faced the highest number of incidents, and a substantial increase started in November. Bogura and Rajshahi had a maximum number of cases from July to August. Dinajpur had a higher number of daily confirmed cases from July to August. A higher number of cases have been recorded in Sylhet from July to September.

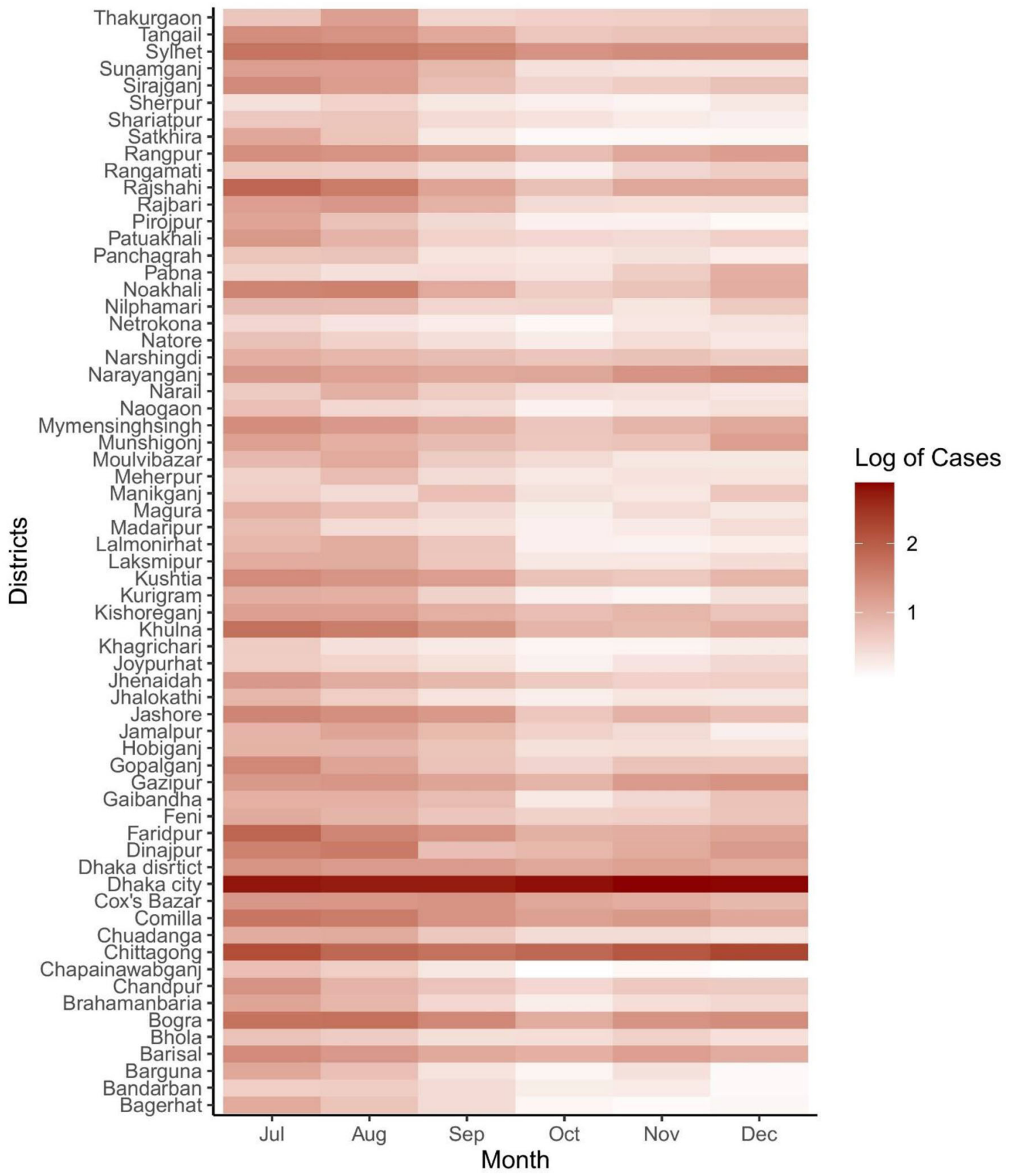

Fig. 3 District-wise dynamics of COVID-19 cases transformed in logarithmic scale of $\log (\mathrm{N}+1)$ 


\subsection{Basic $\left(R_{0}\right)$ and effective reproduction number $\left(\boldsymbol{R}_{\mathrm{t}}\right)$ in Bangladesh}

From Table 1, the overall $R_{0}$ in Bangladesh is assumed to vary around $2.02(1.33-3.28,95 \% \mathrm{CI})$. The overall means under Log-Normal and Gamma distributions were 2.01 $(1.16,3.29,95 \% \mathrm{CI})$ and $2.02(1.51,3.26,95 \% \mathrm{CI})$, respectively (Table 1).

Bangladesh observed a maximum value of $R_{t} 4.15$ (3.43, 4.97, 95\% CI) in late March 2020. A gradual decrease of $R_{\mathrm{t}}$ has been observed from April 1 to April 20, 2020. However, $R_{\mathrm{t}}$ increased from late April 2020 and started to decrease in mid-May. The $R_{\mathrm{t}}$ remained below 1 from midJune to end of July. For a shorter period $R_{\mathrm{t}}$ was above 1 in early August. The $R_{\mathrm{t}}$ reached above 1 from late October to mid-November 2020 and was below 1 from early December 2020 to end of January 2021. However, an upheaval of $R_{\mathrm{t}}$ above 1 has been seen from early February 2021 (Fig. 4).

Figure 5 shows $R_{\mathrm{t}}$ trends at district-level from early July to mid-December 2020. $R_{\mathrm{t}}$ showed a monotonic increase throughout the period and remained above 1.5 in 11 districts (Bagerhat, Bandarban, Chapainawabganj, Joypurhat, Narail, Netrokona, Pirojpur, Rangamati, Satkhira,
Shariatpur, and Sherpur). Bagerhat showed a sharp increase in October and early-December and declined to 1.5 in midDecember. Chapainawabganj reached 3.0 in late-October and remained above 2.0 in mid-December. Satkhira fluctuated between 1.5 and 3.2 from October to December. Other districts either decreased monotonically or remained stable. A noticeable decrease can be seen in Pabna and Panchagarh districts.

\subsection{Spatial trend of monthly effective reproduction number across Bangladesh}

Spatial distribution of mean monthly $R_{\mathrm{t}}$ shows how the spread shaped from July to December in Bangladesh (Fig. 6). Between July and September, $R_{\mathrm{t}}$ fluctuated between below 1 and 1.5 for most of the districts which ramped up in October. In October, $R_{\mathrm{t}}$ fluctuated between 1 and above 2 for almost all districts where the north-western (Chapainowabgonj), the south-western (Satkhira) and northern (Mymensingh) districts had $R_{\mathrm{t}}$ above 2. In November, $R_{\mathrm{t}}$ fluctuated between 1.5 and above 2 for the south-western (Sathkhira and Bagerhat), the north-western (Chapainowabgonj), northern (Lalmonirhat, Nilphamari and Pirojpur) and south-eastern (Khagrachari) districts. In
Table 1 Estimates of $R_{0}$ for COVID-19 in Bangladesh at different serial interval using exponential growth (EG) and maximum likelihood estimate (MLE) methods

\begin{tabular}{|c|c|c|c|}
\hline \multirow[t]{2}{*}{ Serial intervals } & \multirow[t]{2}{*}{ Method } & \multicolumn{2}{|c|}{ Estimated R0 (95\% CI) } \\
\hline & & Log-Normal & Gamma \\
\hline \multirow[t]{2}{*}{ Mean $=6.3, \mathrm{SD}=4.2[20]$} & EG & $1.91(0.94,3.49)$ & $1.90(0.94,3.41)$ \\
\hline & MLE & $2.76(1.65,4.30)$ & $2.75(1.64,4.27)$ \\
\hline \multirow[t]{2}{*}{ Mean $=4.7, \mathrm{SD}=2.9[17]$} & EG & $1.67(0.95,2.77)$ & $1.67(0.95,2.75)$ \\
\hline & MLE & $2.14(1.27,3.31)$ & $2.15(1.29,3.34)$ \\
\hline \multirow[t]{2}{*}{ Mean $=3.96, \mathrm{SD}=4.75[21]$} & EG & $1.51(0.95,2.19)$ & $1.61(0.95,2.41)$ \\
\hline & MLE & $1.74(1.03,2.70)$ & $1.93(1.15,3.00)$ \\
\hline \multirow[t]{2}{*}{ Mean $=4.4, \mathrm{SD}=3.0[22]$} & EG & $1.61(0.95,2.57)$ & $1.62(0.95,2.58)$ \\
\hline & MLE & $1.99(1.19,3.10)$ & $2.02(1.20,3.14)$ \\
\hline \multirow[t]{2}{*}{ Mean $=5.29, \mathrm{SD}=5.34[23]$} & EG & $1.67(0.94,2.65)$ & $1.74(0.94,2.76)$ \\
\hline & MLE & $2.09(1.25,3.26)$ & $2.22(1.32,3.45)$ \\
\hline \multirow[t]{2}{*}{ Mean $=5.2, \mathrm{SD}=1.72[24]$} & EG & $1.80(0.95,3.38)$ & $1.74(0.94,2.76)$ \\
\hline & MLE & $2.51(1.5,3.90)$ & $2.22(1.32,3.45)$ \\
\hline \multirow[t]{2}{*}{ Mean $=3.95, \mathrm{SD}=1.51[24]$} & EG & $1.58(0.96,2.58)$ & $1.58(0.96,2.58)$ \\
\hline & MLE & $1.93(1.15,3.00)$ & $1.93(1.15,2.99)$ \\
\hline \multirow[t]{2}{*}{ Mean $=6.7, \mathrm{SD}=5.2[13]$} & EG & $1.93(0.93,3.49)$ & $1.93(0.93,3.40)$ \\
\hline & MLE & $2.78(1.66,4.32)$ & $2.76(1.65,4.29)$ \\
\hline \multirow[t]{2}{*}{ Mean $=4.56, \mathrm{SD}=0.95[25]$} & EG & $1.70(0.95,3.06)$ & $1.70(0.95,3.06)$ \\
\hline & MLE & $2.20(1.31,3.42)$ & $2.20(1.31,3.42)$ \\
\hline \multirow[t]{2}{*}{ Mean $=4.22, \mathrm{SD}=0.4[25]$} & EG & $1.65(0.96,2.88)$ & $1.64(0.95,2.88)$ \\
\hline & MLE & $2.07(1.24,3.22)$ & $2.04(1.23,3.21)$ \\
\hline \multirow[t]{2}{*}{ Mean $=7.0, \mathrm{SD}=4.5[26]$} & EG & $2.03(0.93,3.94)$ & $2.02(0.93,3.81)$ \\
\hline & MLE & $3.16(1.89,4.92)$ & $3.12(1.86,4.85)$ \\
\hline Overall & & $2.01(1.16,3.29)$ & $2.02(1.51,3.26)$ \\
\hline
\end{tabular}






Fig. 4 Effective reproduction number $\left(R_{\mathrm{t}}\right)$ changes of Bangladesh. The grey regions (Mar-May) show nation-wide lockdown phase

December, south-western (Sathkhira) and north-western (Chapainowabgong) had $R_{\mathrm{t}}$ above 2 .

The mean $R_{\mathrm{t}}$ of post-lockdown period in Bangladesh is shown in Fig. 7. The northern (Sherpur and Netrokona), South-western (Satkhira and Bagerhat), and north-western (Chapainowabgonj) districts of Bangladesh had a higher mean $R_{\mathrm{t}}$.

\subsection{Effectiveness of lockdown measures on the curtailment of COVID-19 transmission in Bangladesh}

Table 2 shows lockdown measures' effectiveness on the curtailment of COVID-19 transmission in Bangladesh. The mean $R_{\mathrm{t}}$ at four lockdown interval periods in Bangladesh. At 15 days of the lockdown phase, the mean $R_{\mathrm{t}}$ was 2.16 $(1.66-2.75,95 \% \mathrm{CI})$, and an increasing trend of $R_{\mathrm{t}}$ was observed at the 30 days of LD $2.37(2.23-2.52,95 \% \mathrm{CI})$ with a relative change of $9.72 \%$. At 45 days of lockdown, $R_{\mathrm{t}}$ plummeted to $1.24(1.21-1.29,95 \% \quad$ CI) with a decreasing relative change of $-47.68 \%$. However, the $R_{\mathrm{t}}$ increased to 1.29 during 60 days of LD (1.21-.29, 95\% CI), implying a $4.03 \%$ increase from 45 days of the LD phase. Considering the total effect of NPIs, containment measures are shown to be moderately effective in reducing $R_{\mathrm{t}}$ by $24.03 \%$.

\subsection{Correlation between COVID-19 cases and population density}

The correlation between population density and COVID-19 cases is shown in Fig. 8. A strong positive correlation was observed between COVID-19 incidence and population density (Pearson's correlation coefficient $r=0.75$ ) with a statistical significance $(p<0.001)$. The linear fit between population density and COVID-19 incidence exhibits a significant positive trend $(p<0.001)$. The coefficient of determination is 0.56 , suggesting population density explains $56 \%$ of COVID-19 cases in Bangladesh.

\section{Discussion}

The main focus of this study was to evaluate the effectiveness of containment measures in Bangladesh using $R_{0}$ and $R_{\mathrm{t}}$. This is probably the first study to estimate the transmission potential and severity of COVID-19 outbreak after the lockdown across Bangladesh. This study finds preliminary $R_{0}$ of Bangladesh was $2.02(1.33-3.28,95 \%$ CI). Our results are similar to previously reported $R_{0}$ in China $[17,27]$ and neighboring country India [28]. After a week of nation-wide lockdown, $R_{\mathrm{t}}$ decreased substantially from early April 2020 in Bangladesh, which corroborates with those of $[29,30]$. Our finding suggests that Bangladesh has seen an upheaval of $R_{\mathrm{t}}$ in early February 2021, which corroborates with Abbott et al. [31].

In response to transmission curtailment, preventive measures have been started in late March 2020 in 


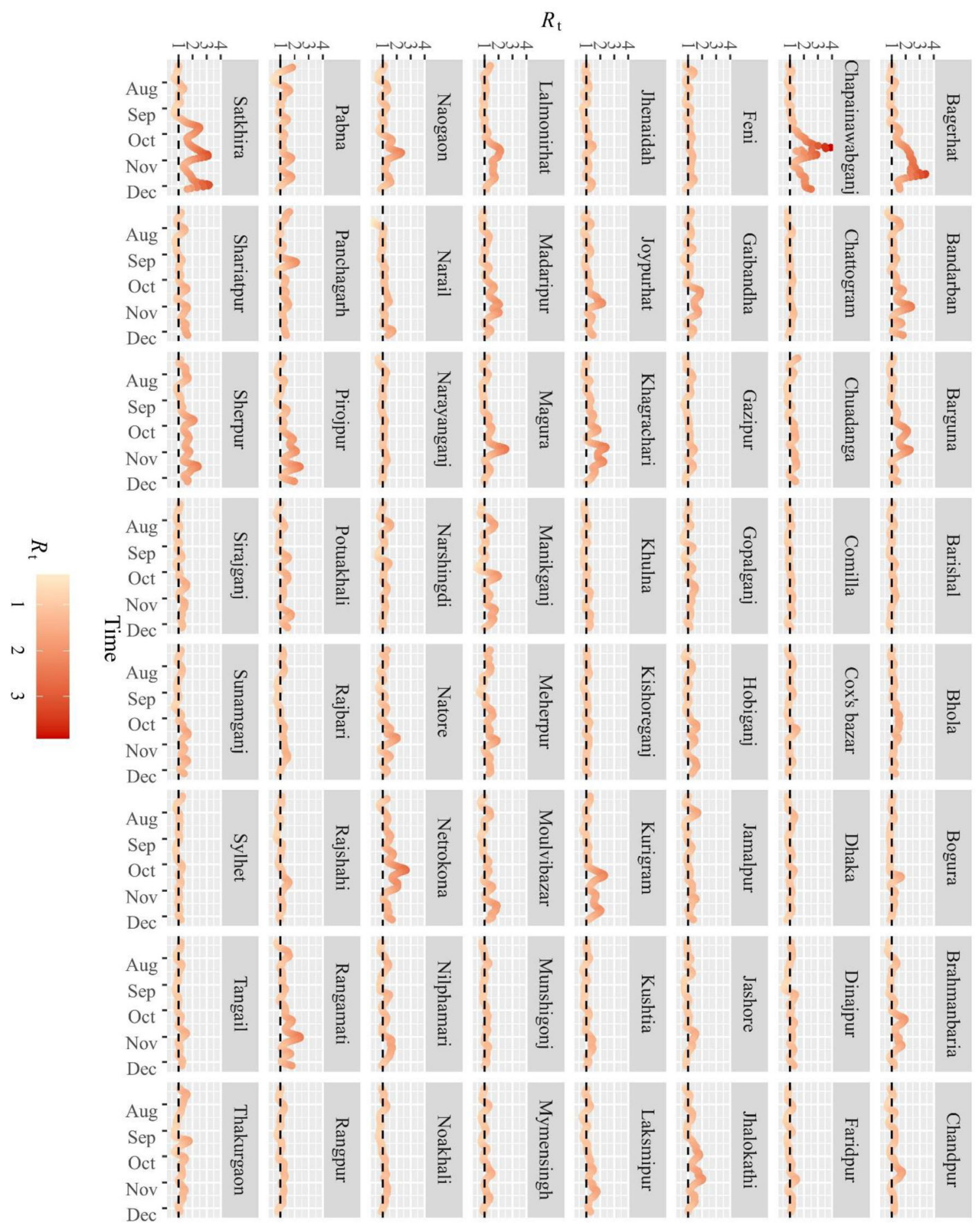

Fig. 5 District-wise effective reproduction number $\left(R_{\mathrm{t}}\right)$ showing linear trend at $95 \%$ confidence interval

Bangladesh. A mass movement occurred by the people of urban centers, particularly from Dhaka, since Dhaka City was the initial outbreak center. On March 25, 2020, the Director of (IEDCR) suspected a limited community transmission was occurring. However, by mid-April, they claimed community transmission went on a large scale. A drastic drop in the testing quantity occurred because of the increased COVID-19 testing charge by the government of Bangladesh $(\mathrm{GoB})$ in late June. It is reported that daily testing rates have dropped to 0.8 tests per 1000 people, and it declined to 0.06 tests per 1000 people in August [32].

The spatial variation of SARS-CoV-2 transmission is observed across Bangladesh. The transmission dynamics might be modulated by several confounding factors (i.e., 

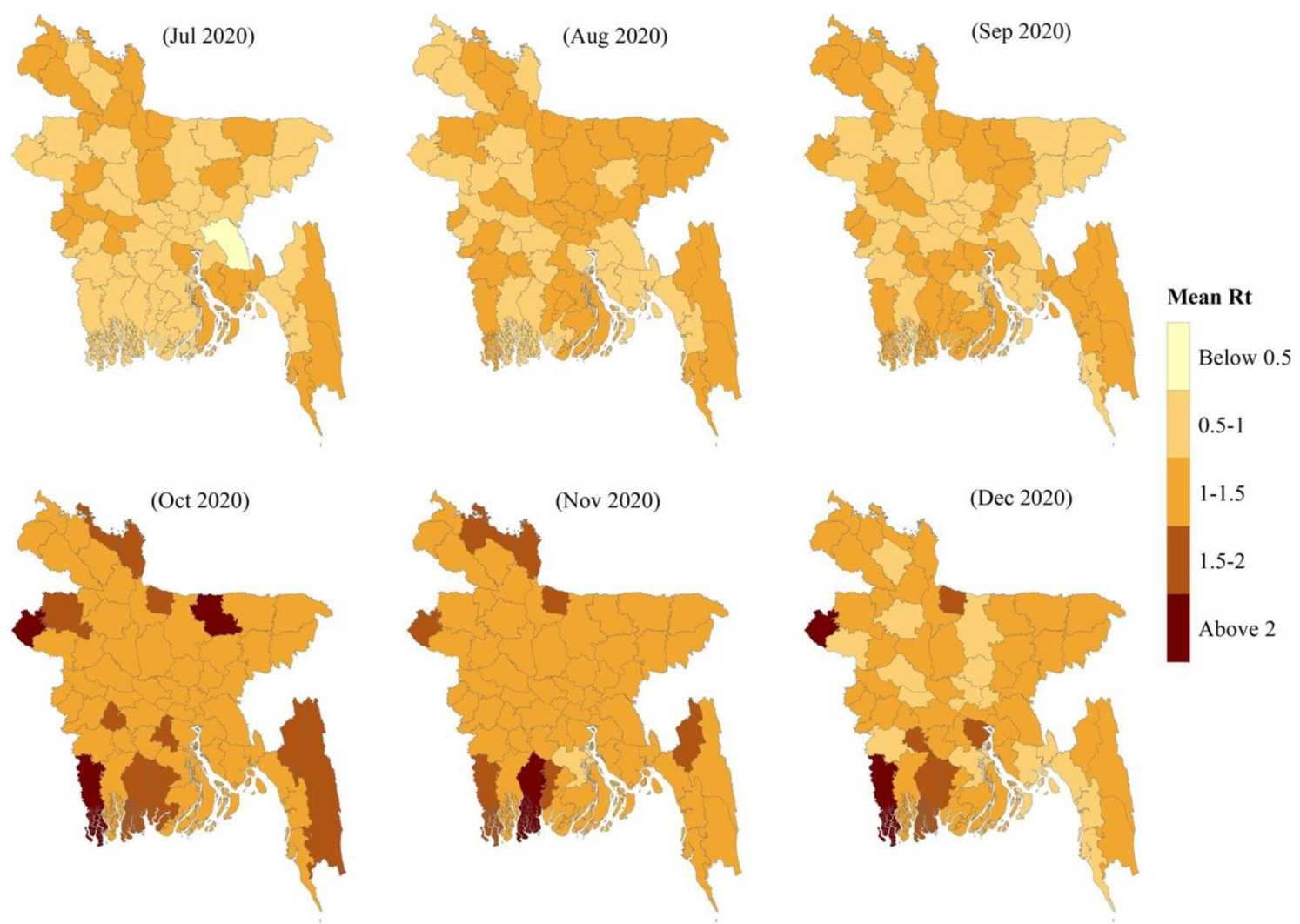

Fig. 6 Post-lockdown spatial trend of average monthly effective reproduction number $\left(R_{\mathrm{t}}\right)$ in Bangladesh at district scale

lockdown, socio-economic, socio-behavioral, bioclimatic, other factors). Islam et al. [33] and Hridoy et al. [4] found a profound effect of meteorological parameters on COVID19 transmission in Bangladesh. Population density is also an influential factor for COVID-19 transmission in Bangladesh $[34,35]$. Due to poor socio-economic conditions, most of population tend to continue daily movements exacerbating transmission. This study suggests a strong positive correlation between COVID-19 cases and population density; this finding corroborates with prior researches in Bangladesh [35-37] and with other countries India [38], USA [6], and Turkey [39]. Moreover, this study found correlation coefficient of 0.75 between population density and COVID-19 cases and explaining 56\% variation in Bangladesh.

To curb the transmission of the contagious disease, the GoB has announced a nation-wide general lockdown from March 26 to May 30, 2020, and then allowed to continue all postponed works, excluding opening educational institutions from May 31, 2020. It is reported that the government of Bangladesh (GoB) will reopen all educational institutions, excluding universities, from March 30, 2021, by giving COVID-19 vaccine to all teachers and staff except students who have age of under 18 years [40]. However, mass mobility of susceptible students may spread the transmission. Furthermore, universities will be reopened from May 24 2021, where precautions are more convincible than schools and colleges. Additionally, the upcoming Eid-Ul-Fitr (one of the annual celebration days of Muslims) event should be under concern regarding the event's potentiality to accelerate the propagation rate of COVID-19.

On 14 December 2020, a new SARS-CoV-2 variant referred to as SARS-CoV-2 VUI 202,012/01 (B.1.1.7) has been identified in the United Kingdom of Great Britain and Northern Ireland [41]. The authorities of Bangladesh did not reveal information about the new UK variant of SARSCoV-2 was first detected in Bangladesh in January 2021 [42]. The new variant is estimated to be $70 \%$ more transmissible than previous circulating variants [41]. Moreover, variant B.1.1.7 is $64 \%$ more lethal than the previously circulating variants [43]. People who catch the new variant are infected for a relatively long time [44]; thus, a more extended quarantine period might be warranted for passengers coming from UK in Bangladesh. Moreover, physical distancing, wearing mask and washing hands practices are not properly maintained in Bangladesh [45]. Thus, with the emergence of a new variant of SARS-CoV-2 and high population density, COVID-19 situation might aggravate in Bangladesh.

In this study, 64 administrative districts of Bangladesh have been analyzed to identify the areas with a higher 
Fig. 7 Mean $R_{\mathrm{t}}$ of post-

lockdown period in Bangladesh

\section{Mean Rt of post-lockdown period}



Table 2 Effectiveness of lockdown measures at different lockdown intervals

\begin{tabular}{llll}
\hline Interval & Effective reproduction number in Bangladesh $(95 \%$ CI $)$ & Relative change $(\%)$ & Total LD effectiveness \\
\hline Before LD & $2.33(1.49-3.34)$ & -7.29 & $-24.03 \%$ \\
15 days of LD & $2.16(1.66-2.75)$ & 9.72 \\
30 days of LD & $2.37(2.23-2.52)$ & -47.68 \\
45 days of LD & $1.24(1.21-1.29)$ & 4.03 \\
60 days of LD & $1.29(1.27-1.32)$ & \\
During LD & $1.77(1.55,1.77)$ & \\
\hline
\end{tabular}




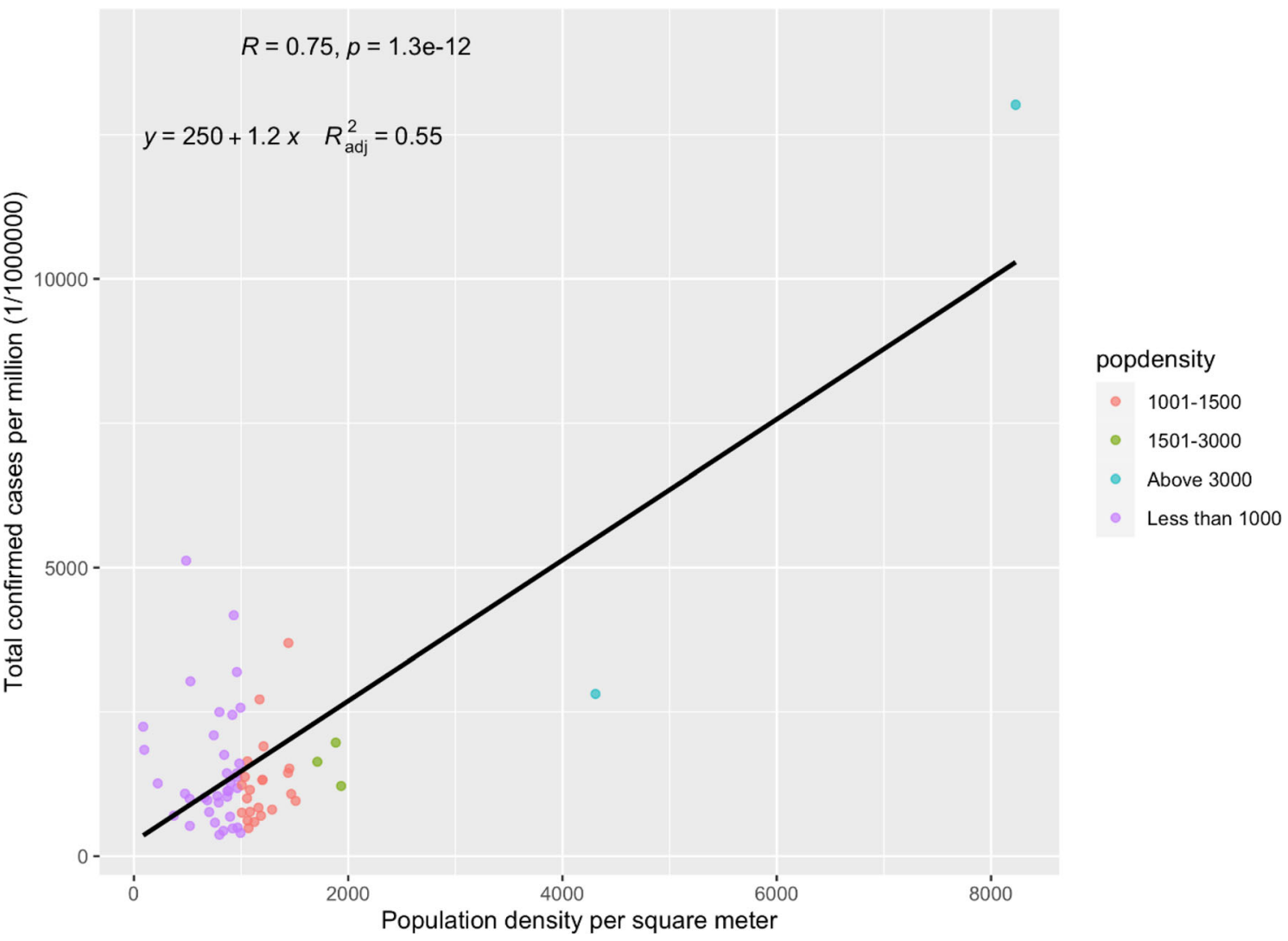

Fig. 8 Correlation between population density and COVID-19 cases

transmission rate. As the dynamism of COVID-19 varies from place to place, it is inevitable to monitor the micro (district) level scenarios of transmission. This study highlights the importance of real-time monitoring of COVID19 transmission, which will help policymakers impose or ease containment measures regarding time and space. Otherwise, a minor regional epidemic has the potentiality to reintroduce an outbreak throughout the country. Moreover, the new variant of SARS-CoV-2 (B.1.1.7) might propagate locally and cause a sustained epidemic.

Our study has some strengths and limitations. This study incorporated a long durational observation of the $R_{\mathrm{t}}$ across Bangladesh and estimated a preliminary basic reproduction number utilizing different serial intervals. We had four notable limitations. Firstly, we estimated the $R_{t}$ using diagnostic report date. However, the $R_{\mathrm{t}}$ should be estimated by symptom onset date. Secondly, the reproduction number estimation heavily depends on the generation time, which may be difficult to get early in an outbreak [46]. Regarding serial interval, as COVID-19 line-list data is not publicly available, we have used serial interval time of other countries, which may not reflect Bangladesh's actual epidemic scenario. Thirdly, $R_{\mathrm{t}}$ estimation might be biased by testing rate, delayed, inconsistent, under-reporting and super-spreaders. Fourthly, district-wise data is not available after mid-December 2020. Therefore, we could not estimate $R_{\mathrm{t}}$ after mid-December 2020. However, real-time monitoring of disease transmission may provide valuable insights into COVID-19 dynamics in Bangladesh. Since the local transmission is sustained, tailored community measures are needed to curb local outbreaks in Bangladesh.

\section{Conclusion}

The study estimated plausible $R_{0}$ in the early outbreak and $R_{\mathrm{t}}$ in Bangladesh. The real-time monitoring of $R_{\mathrm{t}}$ helped us to understand the effectiveness of containment measures adopted by authorities. There is a spatial variation of SARS-CoV-2 transmission in 64 administrative districts of Bangladesh. In August, $R_{\mathrm{t}}$ was above 1 for most districts and fluctuated between 1 and above 2 for almost all districts in October. Overall, the northern (Sherpur and Netrokona), south-western (Satkhira and Bagerhat), and north-western (Chapainowabgonj) districts of Bangladesh had a higher mean $R_{\mathrm{t}}$. This study indicated that the overall $R_{\mathrm{t}}$ of Bangladesh had declined to below 1 from early December 2020. However, a gradual increase of $R_{\mathrm{t}}$ above 1 has been seen from early February 202. Moreover, realtime monitoring of district-wise $R_{\mathrm{t}}$ suggests that there 
might be sustained epidemics in most districts. Since Bangladesh is amid COVID-19 outbreak and situation might aggravate, real-time monitoring of transmissibility is necessary to adopt appropriate measures to contain the transmission.

Acknowledgements The authors would like to thank all the frontline fighters, doctors, healthcare staffs, police forces fighting this pandemic. We are also thankful to the reviewers for their thoughtful suggestions.

Author contributions Conceptualization and approval: Hridoy AE, Rahman SM; methodology: Hridoy AE, Rashid KJ, Naim M; software: Hridoy AE, Rashid KJ, Sami MS; analysis: Hridoy AE, Tusher SMSH; data curation: Hridoy AE; validation: Hridoy AE, Rashid KJ, Rahman SM; draft preparation: Sami MS, Babu MR, Ahmed MS, Tipo IS; visualization: Hridoy AE, Rashid KJ, Naim M; review and editing: Rahman SM, Sami MS, Babu MR, Tipo IS, Tusher SMSH, Ahmed MS, Rashid KJ; supervision: Rahman SM.

Funding This research did not receive any specific grant from funding agencies in the public, commercial, or non-profit organizations.

Data availability COVID-19 Data are available at Johns Hopkins University's GitHub repository (https://github.com/CSSEGI SandData/COVID-19); District-wise COVID-19 incidences are available at (https://docs.google.com/spreadsheets/d/e/2PACX1vQgQAWwlQYF4XTxVT8sYP5wwqz_KxaWfVNQk9B0 FlyPPpDphAIv1cRIMV4ve_1gNbewGjcbkKNpi3Wm/pub?gid= 624602850\#); NPIs information is available at Github repository Oxford Covid-19 Government Response Tracker (OxCGRT) ( https:// github.com/OxCGRT/covid-policy-tracker).

\section{Declarations}

Conflict of interest All authors declare that they have no competing interests.

Consent to participate This study is categorized as low-risk, as only aggregated, publicly-available incidence datasets were used.

\section{References}

1. Delamater, P. L., Street, E. J., Leslie, T. F., Yang, Y. T., \& Jacobsen, K. H. (2019). Complexity of the basic reproduction number (R0). Emerging Infectious Diseases, 25(1), 1. https://doi. org/10.3201/eid2501.171901.

2. Anwar, S., Nasrullah, M., \& Hosen, M. J. (2020). COVID-19 and Bangladesh: challenges and how to address them. Frontiers in Public Health. https://doi.org/10.3389/2Ffpubh.2020.00154.

3. Berkelman, R. L., Bryan, R. T., Osterholm, M. T., LeDuc, J. W., \& Hughes, J. M. (1994). Infectious disease surveillance: a crumbling foundation. Science, 264(5157), 368-370.

4. Hridoy, A. E. E., Mohiman, M. A., Tusher, S. M. S. H., Nowraj, S. Z. A., \& Rahman, M. A. (2021). Impact of meteorological parameters on COVID-19 transmission in Bangladesh: A spatiotemporal approach. Theoretical and Applied Climatology. https://doi.org/10.1007/s00704-021-03535-x.

5. Jahangiri, M., Jahangiri, M., \& Najafgholipour, M. (2020). The sensitivity and specificity analyses of ambient temperature and population size on the transmission rate of the novel coronavirus
(COVID-19) in different provinces of Iran. Science of The Total Environment, 728, 138872. https://doi.org/10.1016/j.scitotenv. 2020.138872.

6. Wong, D. W. S., \& Li, Y. (2020). Spreading of COVID-19: Density matters. PLoS ONE, 15(12), e0242398. https://doi.org/ 10.1371/journal.pone.0242398.

7. Adam, D. (2020). A guide to $\mathrm{R}$ - the pandemic's misunderstood metric. Nature, 583(7816), 346-348. https://doi.org/10.1038/ d41586-020-02009-w.

8. IEDCR. (2020). District wise case number update. IEDCR.

9. BBS. (2011). Statistical yearbook of Bangladesh. Statistics Division, Ministry of Planning, Government of the People's Republic of Bangladesh.

10. Obadia, T., Haneef, R., \& Boëlle, P. Y. (2012). The R0 package: A toolbox to estimate reproduction numbers for epidemic outbreaks. BMC Medical Informatics and Decision Making, 12(1), 1-9. https://doi.org/10.1186/1472-6947-12-147.

11. Fraser, C. (2007). Estimating individual and household reproduction numbers in an emerging epidemic. PLoS One, 2(8), e758. https://doi.org/10.1371/journal.pone.0000758.

12. Cori, A., Ferguson, N. M., Fraser, C., \& Cauchemez, S. (2013). A new framework and software to estimate time-varying reproduction numbers during epidemics. American Journal of Epidemiology, 178(9), 1505-1512. https://doi.org/10.1093/aje/ kwt133.

13. Rotejanaprasert, C., Lawpoolsri, S., Pan-Ngum, W., \& Maude, R. J. (2020). Preliminary estimation of temporal and spatiotemporal dynamic measures of COVID-19 transmission in Thailand. PLoS ONE, 15(9), e0239645. https://doi.org/10.1371/journal.pone. 0239645 .

14. Gostic, K. M., McGough, L., Baskerville, E. B., Abbott, S., Joshi, K., Tedijanto, C., Kahn, R., Niehus, R., Hay, J. A., De Salazar, P. M., Hellewell, J., Meakin, S., Munday, J. D., Bosse, N. I., Sherrat, K., Thompson, R. N., White, L. F., Huisman, J. S., Scire, J., \& Cobey, S. (2020). Practical considerations for measuring the effective reproductive number, Rt. PLOS Computational Biology, 16(12), e1008409. https://doi.org/10.1371/journal.pcbi.1008409.

15. Caicedo-Ochoa, Y., Rebellón-Sánchez, D. E., Peñaloza-Rallón, M., Cortés-Motta, H. F., \& Méndez-Fandiño, Y. R. (2020). Effective Reproductive Number estimation for initial stage of COVID-19 pandemic in Latin American Countries. International Journal of Infectious Diseases, 95, 316-318. https://doi.org/10. 1016/j.ijid.2020.04.069.

16. Al Wahaibi, A., Al Manji, A., Al Maani, A., Al Rawahi, B., Al Harthy, K., Alyaquobi, F., Al-Jardani, A., Petersen, E., \& Al Abri, S. (2020). COVID-19 epidemic monitoring after nonpharmaceutical interventions: The use of time-varying reproduction number in a country with a large migrant population. International Journal of Infectious Diseases, 99, 466-472. https:// doi.org/10.1016/j.ijid.2020.08.039.

17. Nishiura, H., Linton, N. M., \& Akhmetzhanov, A. R. (2020). Serial interval of novel coronavirus (COVID-19) infections. International Journal of Infectious Diseases, 93, 284-286. https:// doi.org/10.1016/j.ijid.2020.02.060.

18. Knight, J., \& Mishra, S. (2020). Estimating effective reproduction number using generation time versus serial interval, with application to COVID-19 in the Greater Toronto Area, Canada. Infectious Disease Modelling, 5, 889-896. https://doi.org/10.1016/j. idm.2020.10.009.

19. Griffin, J., Casey, M., Collins, Á., Hunt, K., McEvoy, D., Byrne, A., McAloon, C., Barber, A., Lane, E. A., \& More, S. (2020). Rapid review of available evidence on the serial interval and generation time of COVID-19. British Medical Journal Open, 10(11), e040263. https://doi.org/10.1136/bmjopen-2020-040263.

20. Bi, Q., Wu, Y., Mei, S., Ye, C., Zou, X., Zhang, Z., Liu, X., Wei, L., Truelove, S. A., Zhang, T., Gao, W., Cheng, C., Tang, X., Wu, 
X., Wu, Y., Sun, B., Huang, S., Sun, Y., Zhang, J., \& Feng, T. (2020). Epidemiology and transmission of COVID-19 in 391 cases and 1286 of their close contacts in Shenzhen, China: A retrospective cohort study. The Lancet Infectious Diseases, 20(8), 911-919. https://doi.org/10.1016/S1473-3099(20)30287-5.

21. Du, Z., Xu, X., Wu, Y., Wang, L., Cowling, B. J., \& Meyers, L. A. (2020). Serial interval of COVID-19 among publicly reported confirmed cases. Emerging Infectious Diseases, 26(6), 1341.

22. Zhao, S., Gao, D., Zhuang, Z., Chong, M. K., Cai, Y., Ran, J., Cao, P., Wang, K., Lou, Y., Wang, W., Yang, L., He, D., \& Wang, M. H. (2020). Estimating the serial interval of the novel coronavirus disease (COVID-19): A statistical analysis using the public data in Hong Kong from January 16 to February 15, 2020 [Preprint]. Epidemiology. https://doi.org/10.1101/2020.02.21.20026559.

23. Du, Z., Xu, X., Wu, Y., Wang, L., Cowling, B. J., \& Meyers, L. A. (2020). COVID-19 serial interval estimates based on confirmed cases in public reports from 86 Chinese cities. MedRxiv. https://doi.org/10.1101/2020.04.23.20075796.

24. Ganyani, T., Kremer, C., Chen, D., Torneri, A., Faes, C., Wallinga, J., \& Hens, N. (2020). Estimating the generation interval for coronavirus disease (COVID-19) based on symptom onset data, March 2020. Eurosurveillance, 25(17), 2000257. https://doi.org/ 10.2807/1560-7917.ES.2020.25.17.2000257.

25. Tindale, L., Coombe, M., Stockdale, J. E., Garlock, E., Lau, W. Y. V., Saraswat, M., \& Colijn, C. (2020). Transmission interval estimates suggest pre-symptomatic spread of COVID-19. MedRxiv. https://doi.org/10.1101/2020.03.03.20029983.

26. Wu, J. T., Leung, K., Bushman, M., Kishore, N., Niehus, R., de Salazar, P. M., \& Leung, G. M. (2020). Estimating clinical severity of COVID-19 from the transmission dynamics in Wuhan, China. Nature Medicine, 26(4), 506-510. https://doi.org/10.1038/ s41591-020-0822-7.

27. Jung, S., Akhmetzhanov, A. R., Hayashi, K., Linton, N. M., Yang, Y., Yuan, B., Kobayashi, T., Kinoshita, R., \& Nishiura, H. (2020). Real-time estimation of the risk of death from novel coronavirus (COVID-19) infection: Inference using exported cases. Journal of Clinical Medicine, 9(2), 523. https://doi.org/10. 3390/jcm9020523.

28. Gupta, M., Mohanta, S. S., Rao, A., Parameswaran, G. G., Agarwal, M., Arora, M., Mazumder, A., Lohiya, A., Behera, P., Bansal, A., Kumar, R., Meena, V. P., Tiwari, P., Mohan, A., \& Bhatnagar, S. (2021). Transmission dynamics of the COVID-19 epidemic in India and modeling optimal lockdown exit strategies. International Journal of Infectious Diseases, 103, 579-589. https://doi.org/10.1016/j.ijid.2020.11.206.

29. Nouvellet, P., Bhatia, S., Cori, A., Ainslie, K. E. C., Baguelin, M., Bhatt, S., Boonyasiri, A., Brazeau, N. F., Cattarino, L., Cooper, L. V., Coupland, H., Cucunuba, Z. M., Cuomo-Dannenburg, G., Dighe, A., Djaafara, B. A., Dorigatti, I., Eales, O. D., van Elsland, S. L., Nascimento, F. F., \& Donnelly, C. A. (2021). Reduction in mobility and COVID-19 transmission. $\mathrm{Na}$ ture Communications, 12(1), 1090. https://doi.org/10.1038/ s41467-021-21358-2.

30. Khan, I. M., Haque, U., Kaisar, S., \& Rahman, M. S. (2021). A computational modeling study of covid-19 in bangladesh. The American Journal of Tropical Medicine and Hygiene, 104(1), 66-74. https://doi.org/10.4269/ajtmh.20-0757.

31. Abbott, S., Hellewell, J., Thompson, R. N., Sherratt, K., Gibbs, H. P., Bosse, N. I., Munday, J. D., Meakin, S., Doughty, E. L., Chun, J. Y., Chan, Y.-W.D., Finger, F., Campbell, P., Endo, A., Pearson, C. A. B., Gimma, A., Russell, T., CMMID COVID modelling group, Flasche, S., \& Funk, S. (2020). Estimating the timevarying reproduction number of SARS-CoV-2 using national and subnational case counts. Wellcome Open Research, 5, 112. https://doi.org/10.12688/wellcomeopenres.16006.2.
32. Cousins, S. (2020). Bangladesh's COVID-19 testing criticised. The Lancet, 396(10251), 591. https://doi.org/10.1016/S01406736(20)31819-5.

33. Islam, A. R. M. T., Hasanuzzaman, M., Azad, M. A. K., Salam, R., Toshi, F. Z., Khan, M. S. I., \& Ibrahim, S. M. (2020). Effect of meteorological factors on COVID-19 cases in Bangladesh. Environment, Development and Sustainability. https://doi.org/10. 1007/s10668-020-01016-1.

34. Islam, A., Sayeed, M. A., Rahman, M. K., Ferdous, J., Islam, S., \& Hassan, M. M. (2021). Geospatial dynamics of COVID-19 clusters and hotspots in Bangladesh. Transboundary and Emerging Diseases. https://doi.org/10.1111/tbed.13973.

35. Sarkar, S. K., Ekram, K. M. M., \& Das, P. C. (2021). Spatial modeling of COVID-19 transmission in Bangladesh. Spatial Information Research. https://doi.org/10.1007/s41324-02100387-5.

36. Alam, M. Z. (2021). Is population density a risk factor for communicable diseases like covid-19? A case of bangladesh. Asia Pacific Journal of Public Health. https://doi.org/10.1177/ 1010539521998858.

37. Sharif, N., \& Dey, S. K. (2021). Impact of population density and weather on COVID-19 pandemic and SARS-CoV-2 mutation frequency in Bangladesh. Epidemiology and Infection, 149, e16. https://doi.org/10.1017/S0950268821000029.

38. Bhadra, A., Mukherjee, A., \& Sarkar, K. (2021). Impact of population density on Covid-19 infected and mortality rate in India. Modeling Earth Systems and Environment, 7(1), 623-629. https://doi.org/10.1007/s40808-020-00984-7.

39. Coşkun, H., Yıldırım, N., \& Gündüz, S. (2021). The spread of COVID-19 virus through population density and wind in Turkey cities. Science of The Total Environment, 751, 141663. https:// doi.org/10.1016/j.scitotenv.2020.141663.

40. Rahman, K. N. (2021, February 27). Bangladesh set to inoculate teachers on priority basis ahead of school reopening. $B d$ news24.com. https://bdnews24.com/bangladesh/2021/02/27/ban gladesh-set-to-inoculate-teachers-on-priority-basis-ahead-ofschool-reopening.

41. World Health Organization. (2020, December 24). SARS-CoV-2 Variant - United Kingdom of Great Britain and Northern Ireland. World Health Organization. https://www.who.int/csr/don/21december-2020-sars-cov2-variant-united-kingdom/en/.

42. Covid-19: New variant detected in 6 UK returnees. (2021, March 10). Dhaka Tribune. https://www.dhakatribune.com/world/europe/ 2021/03/10/covid-19-new-variant-detected-in-6-uk-returnees.

43. Challen, R., Brooks-Pollock, E., Read, J. M., Dyson, L., TsanevaAtanasova, K., \& Danon, L. (2021). Increased hazard of mortality in cases compatible with SARS-CoV-2 variant of concern 202012/1-a matched cohort study. MedRxiv. https://doi.org/10. 1101/2021.02.09.21250937.

44. Nature Editorial. (2021, March 19). COVID research updates: Older people are at higher risk of getting COVID twice. $\mathrm{Na}$ ture. https://doi.org/10.1038/d41586-020-00502-w.

45. Study: Over $60 \%$ people struggle to maintain social distancing in public. (2020, August 27). Dhaka Tribune. https://www.dhaka tribune.com/health/2020/08/27/study-over-60-people-struggle-tomaintain-social-distancing-in-public.

46. Yuan, J., Li, M., Lv, G., \& Lu, Z. K. (2020). Monitoring transmissibility and mortality of COVID-19 in Europe. International Journal of Infectious Diseases, 95, 311-315. https://doi.org/10. 1016/j.ijid.2020.03.050.

Publisher's Note Springer Nature remains neutral with regard to jurisdictional claims in published maps and institutional affiliations. 